relative to œstrin from these determinations owing to the extremely slow absorption. These tests must therefore be regarded as qualitative reactions for œstrogenic activity, but the results are none the less conclusive. The $9: 10$-dihydroxy-9:10-di-n-butyl$9: 10$-dihydro-1:2:5:6-dibenzanthracene, when injected in the quantity described above, gave a full cestrous response in all the ten animals injected, and the ostrus is continuing after 150 hours. With regard to the two carcinogenic hydrocarbons, 5:6-cyclopenteno-1:2-benzanthracene gave four œstrous responses lasting 150 hours out of ten animals, whilst 1:2-benzpyrene gave three œstrous responses lasting 150 hours out of ten animals. It would appear from these results that these two latter compounds have a feebler œstrus-producing action than the former.

In reporting these very suggestive results, we wish expressly to emphasise that, at the present stage, there is no evidence whatever that carcinogenic compounds arise from œstrin in the animal body. We merely record our observations that pure synthetic compounds of known molecular structure can possess both carcinogenic and ostrogenic activity.

We have commenced experiments (in collaboration with Mr. C. L. Hewett and Mr. W. Lawson) which have as their aim the synthesis of ketohydroxyœstrin and compounds of allied structure.

J. W. Cook.

E. C. Dodos.

Research Institute,

Cancer Hospital (Free),

Fulham Road, S.W.3.

Courtauld Institute of Biochemistry, Middlesex Hospital, W.1. Feb. 3.

${ }^{1}$ Rosenheim and King, Chemistry and Industry, 51, 464; 1932. Wieland and Dane, Z. Physiol. Chem., 210, 268; 1932.

${ }_{2}^{2}$ Kennaway and Cook, Chemistry and Industry, 51, 521 ; 1932.

s Girard, C. R. Acad. Sci., 195, 981; 1932; 196, 137; 1933.

- Cook, Dodds and Hewett, NATURE, 131, 56, Jan. 14, 1933.

$s$ Cook, J. Chem. Soc., 496; 1931.

- Cook, $j$. Chem. Soc., 2529; 1931.

' Cook, Hewett and Hieger, NATure, 130, 926, Dec. 17, 1932.

\section{Glutathione, Iodoacetic Acid and Glucose Metabolism}

WiтH reference to Dr. Dickens's interesting letter in NATURE of January 21 (p. 130) I may, perhaps, be allowed to make a brief statement. My colleague, Mr. A. H. M. Wheatley, and I submitted for publication in the Biochemical Journal on November 1 a paper containing the following observations.

(1) The toxicity of iodoacetic acid in vivo is greatly diminished or eliminated by admixture with sodium thiosulphate. Iodimetric estimations showed that one molecule of iodoacetic acid combines with one molecule of sodium thiosulphate.

(2) The powerful inhibitory action of small concentrations of iodoacetic acid on the oxidation of glucose by brain tissue is diminished or eliminated by the addition to the brain tissue of glutathione, cysteine or sodium thiosulphate. The evidence showed that there is a direct interaction between the sulphur compounds and iodoacetic acid, the halogen atom of this acid being clearly very labile. Dr. Dickens's observations support this conclusion.

(3) It appeared possible from the evidence that the toxicity of iodoacetic acid towards biological processes might be linked with its ability to combine easily with sulphydryl compounds, and, hence, that the naturally occurring sulphydryl compound, glutathione, might be playing some part in the processes inhibited by the halogen acid. This conclusion was confirmed by experiments on the action of glutathione on the fermentation of glucose by baker's yeast under aerobic conditions. It was shown that the addition of glutathione to baker's yeast increases the rate of carbon dioxide output in presence of glucose to a value approaching that obtained by the yeast under anaerobic conditions. The oxygen uptake, on the other hand, was slightly inhibited by the presence of the sulphydryl compound. Glutathione affects markedly the relationship between fermentation and the respiration of yeast in the presence of glucose.

The observations recorded above were made before the appearance of Lohmann's paper on the influence of glutathione on glyoxalase activity. It is likely that there is a close connexion between the effects of glutathione on glucose breakdown on one hand and glyoxalase activity on the other, and the conclusion seems warranted that glutathione in the living cell plays a dominant rôle in the dynamies of glucose metabolism.

Biochemical Laboratory,

Cardiff City Mental Hospital.

J. H. QuAstel. Jan. 28.

\section{Rate of Burning of Colloidal Propellants}

In Nature of January 14, A. D. Crow and W. E. Grimshaw have discussed our method of analysing some of their experimental results, and offer the following criticisms :

(1) The method of correcting for energy losses is invalid when applied to differential methods of analysis.

(2) A simplifying approximation we make in calculating the correction leads to serious error.

The first criticism is beside the point, since our method is not a differential method. After adequate trial we discarded both differential and integrating methods and our reasons for doing so are stated in our paper. Our method is a direct method, each point on our curves being based on one observation and one only of pressure and time, independent of previous and subsequent observations. The cooling correction applied at each point is based on the same assumption as that of Crow and Grimshaw, namely, a mean gas temperature holding up to the moment under observation. This assumption is sufficient for the purpose of assessing the energy loss up to this moment, provided the mean temperature does not differ greatly from that at complete combustion. Except for the first two or three observations of each series (which we discard) this condition holds. The resulting corrections to the observations retained are never large enough to mask the effect under investigation.

The simplifying approximation referred to in the second criticism leads to errors of less than one per cent for all observations retained; the resulting displacement of the points on our curves is imperceptible.

The promise of additional material including temperature observations relieves us of the necessity of pursuing this subject further in its present form. F. R. W. HUNT.

Military College of Science, G. H. Hinds. Jan. 23. 